\title{
Research bodies vow to share data on Zika
}

\section{Zosia Kmietowicz}

\section{The BMJ}

Academic journals, charities, research funders, and institutes have committed themselves to sharing data and results relevant to the current Zika virus outbreak and future public health emergencies as rapidly and openly as possible.

The organisations, including the Bill and Melinda Gates Foundation, Médecins Sans Frontières, the US National Institutes of Health, and the UK health research charity the Wellcome Trust, along with leading academic journals such as The BMJ, Nature, Science, and the New England Journal of Medicine, have signed a joint declaration and hope that other bodies will add their names to the statement in the coming weeks.

The statement is intended to ensure that any information that might have value in combating the Zika outbreak is made available to all, free of charge, as soon as is feasibly possible. Journal signatories have said that doing this would not preclude researchers from subsequently publishing papers in their titles. Jeremy Farrar, director of the Wellcome Trust and a signatory to the statement, said, "Research is an essential part of the response to any global health emergency. This is particularly true for Zika, where so much is still unknown about the virus, how it is spread, and the possible link with microcephaly.

"It's critical that as results become available they are shared rapidly in a way that is equitable, ethical, and transparent. This will ensure that the knowledge gained is turned quickly into health interventions that can have an impact on the epidemic." 


\section{Signatories to the statement}

Academy of Medical Sciences, UK

Bill and Melinda Gates Foundation

Biotechnology and Biological Sciences Research Council

The BMJ

Bulletin of the World Health Organization

Canadian Institutes of Health Research

US Centers for Disease Control and Prevention

Chinese Academy of Sciences

Chinese Centre for Disease Control and Prevention

Department of Biotechnology, Government of India

Department for International Development, UK

Deutsche Forschungsgemeinschaft

elife

Economic and Social Research Council, UK

F1000

Fondation Mérieux

Fundação Oswaldo Cruz (Fiocruz)

Institut Pasteur

Japan Agency for Medical Research and Development

JAMA Network

Lancet

Médecins Sans Frontières/Doctors Without Borders (MSF)

National Academy of Medicine

National Institutes of Health, US

National Science Foundation, US

New England Journal of Medicine

PLoS

Science journals

South African Medical Research Council

Springer Nature

UK Medical Research Council

Wellcome Trust

ZonMw (Netherlands Organisation for Health Research and Development) 